Erratum

\title{
Erratum to "Trimethoxystilbene Reduces Nuclear Factor Kappa B, Interleukin-6, and Tumor Necrosis Factor- $\alpha$ Levels in Rats with Pulmonary Artery Hypertension"
}

\author{
Jie Shu, Wei Liu, Fei Han, and Fanyan Luo \\ The Department of Cardiothoracic Surgery, Xiangya Hospital, Central South University, Changsha, Hunan Province, China \\ Correspondence should be addressed to Fanyan Luo; drlfy1998@csu.edu.cn \\ Received 9 July 2020; Accepted 10 July 2020; Published 11 September 2020 \\ Copyright ( 2020 Jie Shu et al. This is an open access article distributed under the Creative Commons Attribution License, which \\ permits unrestricted use, distribution, and reproduction in any medium, provided the original work is properly cited.
}

In the article titled "Trimethoxystilbene Reduces Nuclear Factor Kappa B, Interleukin-6, and Tumor Necrosis Factor$\alpha$ Levels in Rats with Pulmonary Artery Hypertension" [1], information was omitted in the Authors' Contributions section. The corrected section appears below:

\section{Authors' Contributions}

Jie Shu and Wei Liu are joint first co-authors.

\section{References}

[1] J. Shu, W. Liu, F. Han, and F. Luo, "Trimethoxystilbene reduces nuclear factor kappa B, interleukin-6, and tumor necrosis Factor- $\alpha$ Levels in rats with pulmonary artery hypertension," BioMed Research International, vol. 2019, Article ID 1219848, 8 pages, 2019. 